\title{
The impact of serum visfatin, and resistin levels on insulin resistance in
} patients with polycystic ovary syndrome

\begin{abstract}
Background and objective: Women with polycystic ovary syndrome serve as a model to estimate the functions of insulin resistance and chronic hyperinsulinemia on serum level of insulin resistance markers. This study aimed to determine the association of the serum visfatin, resistin levels with insulin resistance in patients with polycystic ovary syndrome, and its correlations with various parameters.
\end{abstract}

Methods: This case-control study was performed at the College of Pharmacy, Hawler Medical University in the period between May 2017 and July 2018. It included 100 patients and 100 age matched healthy control group was also enrolled for comparing purposes.

Results: Patients had significantly elevated serum visfatin ( 2.46 vs. $1.08 \mathrm{ng} / \mathrm{ml}$ ), resistin (3.87 vs. $2.46 \mathrm{ng} / \mathrm{ml})$, and insulin $(17.22 \mathrm{vs} .8 .1 \mu \mathrm{lU} / \mathrm{ml})$ levels than controls. They also had significant elevations in insulin resistance (2.41 vs. 1.92) and $\beta$ insulin function (94.45 vs. 86.98). There was no significant variation in insulin sensitivity (88.77 vs. 92.08$)$.

Conclusion: There was an association between resistin, visfatin, and polycystic ovary syndrome-related insulin resistance. Many recent proteins are now considered as potential new markers of insulin resistance in polycystic ovary syndrome. There was a strong connection between visfatin and resistin with insulin resistance in polycystic ovary syndrome pathophysiology.

Keywords: Insulin; Insulin resistance; Polycystic ovarian syndrome; Resistin; Visfatin.

\section{Introduction}

Polycystic ovary syndrome (PCOS) is a hormonal disorder that affects between $5-10 \%$ women of reproductive age and remains the most enigmatic reproductive disorders. PCOS is the most important endocrine-metabolic disorder in reproductive females, which is linked with metabolic complications, and insulin resistance (IR) that plays an important role in the development and persistence of this disorder. ${ }^{1}$ PCOS is associated with an increased incidence of IR, obesity, and type 2 diabetes. The most common symptoms of PCOS are IR and irregular menstrual cycles. The role of IR in PCOS has been founded and recognized. The homeostatic model assessment of IR (HOMA-IR) is an important method for IR measurement used in scientific studies because it is a simple and noninvasive, and inexpensive technique. ${ }^{2}$ The occurrence of PCOS for long term consequences type 2 diabetes mellitus, hypertension, and cardiovascular disease. ${ }^{3}$ Many surrogate markers are needed to facilitate the estimation of IR. Many new proteins are strongly involved with PCOS physiopathology and IR, such as visfatin and resistin, but their roles are still controversial. IR and hyperinsulinemia determine hyperandrogenemia stimulating ovarian theca cells to secrete androgens and increasing $\mathrm{LH}$ effect on ovarian androgen production. Both androgens and insulin inhibit sex hormone binding globulin (SHBG) secretion, increasing free and bioactive androgen levels, and making

${ }^{1}$ Department of Clinical Analysis, College of Pharmacy, Hawler Medical University, Erbil, Iraq.

${ }^{2}$ Department of Chemistry, Faculty of Science, University of Kufa, Kufa, Iraq.

* Correspondence: shatha003@yahoo.com 
clinical androgen excess worse. Moreover, IR is critically included in the occurrence of metabolic syndrome and cardiovascular disease in PCOS women, that is why its treatment (lifestyle changes, insulinsensitizing drugs, and bariatric surgery) is thought to be important for both to reduce IR and to improve its consequences. ${ }^{4}$ Adipokines such as resistin and visfatin are secreted by white adipose tissues, which are considered to be active contributors in glucose homeostasis. Recently, this evidence has become robust, emphasizing that obesity and inflammation are major components of IR. One of the mechanisms described in patients with metabolic syndrome characterized by increased visceral adipose tissue is that long-term exposure to an excess of dipokine levels leads to a chronic sub inflammatory status that is participated in the occurrence of IR. ${ }^{5}$ In most individuals, IR and obesity coexist. The degree of adipose tissue and inflammation, not obesity per se, are preconditions for the occurrence of IR. ${ }^{6}$

Resistin: is an adipose-derived peptide hormone discovered in 2001. The role of resistin in IR of PCOS is still controversial. Resistin, an adipocytokine, may represent a link between obesity, and metabolic disorders PCOS. ${ }^{7}$

Visfatin: It is anadipokine preferentially expressed in visceral adipose tissue, exerts proinflammatory and immunomodulating properties and was described to be higher in obese subjects. ${ }^{8}$ Visfatin also has insulin-sensitizing and insulin-mimetic effect stimulating glucose uptake in adipocytes and suppressing glucose production from liver cells in vitro, ${ }^{9}$ so attention attracts its possible application in glycemic control.

This study aimed to investigate the ability of biomarkers visfatin and resistin to predict IR in PCOS and its correlations with various parameters.

\section{Methods}

This case-control study was performed at the College of Pharmacy, Hawler Medical
University in the period between May 2017 and July 2018. It included 100 reproductive women with PCOS with their age ranging from 22 to 34 year. Another 100 apparently healthy women were enrolled as a control group with the mean age of $28.73 \pm 7.40$ year, which was comparable to that of patients. None of these subjects were pregnant, irregular periods, or have other endocrine disorders.

They were 6-8 hours overnight fasting and on treatment with metformin $\left(\right.$ Glucophage $^{\circledR}$ ). All the participated women were having polycysts in their ovaries by ultrasonography examination. The BMI was calculated from the following equation: $\mathrm{BMI}=$ Weight $(\mathrm{Kg}) /$ Height $\left(\mathrm{m}^{2}\right)$. When BMI was larger than $30 \mathrm{Kg} / \mathrm{m}^{2}$, the person was defined as obese. All PCOS patients were evaluated for serum luteinizing hormone (LH), follicle stimulating hormone (FSH) and estradiol, total testosterone, free testosterone. All hormones were estimated using the enzyme-linked immunosorbent assay (ELISA) technique. The estimation of serum glucose, provided by Biolabo, France. The computer based HOMA2 calculator (available at www.dtu.ox.ac.uk/ homa) using fasting glucose and insulin to generate the index of IR, HOMA2IR, and the index of $\beta$ cell function (HOMA- $\% B$ ). In ideal normal-weight individual age $<35$ years had HOMA2IR of $1 \mathrm{~mol} . \mu \mathrm{U} / \mathrm{L}^{2}$ and HOMA-\% B cell function of $100 \%$.

Sample Collection: Ten milliliters fasting blood samples (6-8) hours were extracted from the participants, blood samples were kept at room temperature for $30 \mathrm{~min}$ for coagulation, and then centrifuged for $15 \mathrm{~min}$ at 2500-3500 rpm. Sera were separated and divided into several portions and then placed into plastic plain tubes for routine biochemical tests, which were performed immediately after the serum was separated. The remaining sera were stored at $-80{ }^{\circ} \mathrm{C}$ till the day of the analysis within 2-3 months. The sera samples were prepared for measurement by warming the frozen sera at room temperature. Both groups were completed the baseline 
questionnaire concerning several risk $\mathrm{ml}$ ), resistin (3.87 vs. $2.46 \mathrm{ng} / \mathrm{ml})$ levels

factors.

Statistical Analysis: The results were expressed as mean \pm standard deviation. t-test was used for the comparison between the patients and control groups and among subdivided groups in the measured parameters. Pearson's correlation coefficients $(r)$ were calculated to estimate the correlation between parameters. For the nonparametric variables, that is not normally distributed. The difference between groups was considered as statistically significant when $P<0.05$. All the statistical analyses were performed using the statistical package for the social sciences (version 20), IBM-USA. While the figures were constructed using Excel program of Microsoft Office 2007.

\section{Results}

Patients with PCOS had significantly elevated in serum visfatin (2.46 vs. $1.08 \mathrm{ng} /$ than age-matched healthy controls. Women with PCOS had significantly higher serum insulin levels (17.22 vs. $8.1 \mu \mathrm{lU} / \mathrm{ml})$, significant elevations in $\mathrm{IR}(2.41$ vs. 1.92), and $\beta$ insulin function (94.45 vs. 86.98). There was no significant variation in insulin sensitivity (88.77 vs. 92.08). There were elevations in the serum FSH11.89 vs. $11.10 \mathrm{mlU} / \mathrm{ml}$, prolactin $(13.20$ vs. $11.97 \mathrm{ng} / \mathrm{ml}$ ), progesterone $0.97 \pm 0.04$ vs. $0.94 \pm 0.04 \mathrm{ng} / \mathrm{ml}$, but did not reach significant levels. There were significant elevations in the serum levels of testosterone $(4.18$ vs. $3.58 \mathrm{pg} / \mathrm{ml} ; 0.9 \pm 0.23$ vs. $0.71 \pm 0.32$, for free and total forms respectively) in the patients' group as compared with the control group. In addition, there were significant elevations in serum levels of LH (14.12 vs. $11.13 \mathrm{mIU} /$ $\mathrm{ml}$ ) and estrogen 2 levels (67.58 vs. $38.69 \mathrm{pg} / \mathrm{ml}$ ) (Table 1).

Table 1: Comparison between patient and control group regarding all studied parameters.

\begin{tabular}{lccc}
\hline \multicolumn{1}{c}{ Parameter } & $\begin{array}{c}\text { PCOS Patients } \\
\mathbf{n}=\mathbf{1 0 0}\end{array}$ & $\begin{array}{c}\text { Controls } \\
\mathbf{n}=100\end{array}$ & $\boldsymbol{P}$ value \\
\hline Age $($ year) & $28.28 \pm 6.48$ & $27.98 \pm 7.10$ & 0.093 \\
BMl $\left(\mathrm{kg} / \mathrm{m}^{2}\right)$ & $28.72 \pm 4.66$ & $26.23 \pm 3.48$ & 0.012 \\
W/H ratio & $0.91 \pm 0.13$ & $0.81 \pm 0.86$ & 0.024 \\
FBS $(\mathrm{mg} / \mathrm{ml})$ & $92.13 \pm 19.26$ & $89.88 \pm 21.23$ & 0.072 \\
Insulin $(\mu \mathrm{lU} / \mathrm{ml})$ & 17.22 & 8.10 & 0.008 \\
HOMA2IR & 2.41 & 1.92 & 0.011 \\
HOMA\%B & 94.45 & 86.98 & 0.033 \\
HOMA\%S & 88.77 & 92.08 & 0.71 \\
FSH $(\mathrm{mlU} / \mathrm{ml})$ & 11.89 & 11.10 & 0.64 \\
LH $(\mathrm{mlU} / \mathrm{ml})$ & 14.12 & 11.13 & 0.017 \\
LH/FSH & 1.39 & 1.57 & 0.65 \\
E2 $(\mathrm{pg} / \mathrm{ml})$ & 67.58 & 38.69 & $<0.001$ \\
Prolactin $(\mathrm{ng} / \mathrm{ml})$ & 13.20 & 11.97 & 0.72 \\
Progesterone $(\mathrm{ng} / \mathrm{ml})$ & $0.97 \pm 0.04$ & $0.94 \pm 0.04$ & 0.62 \\
F.Testo. $(\mathrm{pg} / \mathrm{ml})$ & 4.18 & 3.58 & 0.041 \\
T.Testo. $(\mathrm{ng} / \mathrm{ml})$ & $0.9 \pm 0.23$ & $0.71 \pm 0.32$ & 0.021 \\
Visfatin $(\mathrm{ng} / \mathrm{ml})$ & 2.46 & 1.08 & $<0.001$ \\
Resistin $(\mathrm{ng} / \mathrm{ml})$ & 3.87 & 2.46 & 0.003 \\
\hline
\end{tabular}


Table 2 illustrates that there was a negative, weak significant correlation between age and resistin $(r=-0.406$, $P=0.001$ ). Table 3 shows the presence of a positive weak significant correlations between resistin with progesterone, and free testosterone ( $r=0.449, P<0.001$; $r=0.449, P<0.001$, respectively). Table 4 reveals that there was a negative, weak significant correlation between visfatin and age ( $r=-0.247, P=0.034)$ as well as a positive weak significant correlation between visfatin and beta cell function $(r=0.262, P=0.048)$. Table 5 shows the presence of a positive weak significant correlations between visfatin and $\mathrm{LH}, \mathrm{LH} / \mathrm{FSH}$ ratio, progesterone, and free testosterone $(r=0.275, P=0.034$; $\mathrm{r}=0.298, P=0.021 ; \mathrm{r}=0.449, P<0.001$; $\mathrm{r}=0.351, P=0.006$. respectively).

Table 2: Correlations of resistin with age, obesity, and IR parameters in the PCOS group.

\begin{tabular}{|c|c|c|c|c|c|c|c|c|c|}
\hline & & Age & BMI & WHR & Sugar & Insulin & $\underset{\text { IR }}{\text { HOMA2 }}$ & НОМА\%В & HOMA \%S \\
\hline \multirow{3}{*}{ Resistin } & $r$ & $-0.406^{* *}$ & 0.074 & 0.001 & -0.14 & -0.027 & -0.019 & 0.118 & -0.052 \\
\hline & & & & & & & & & \\
\hline & $\mathrm{P}$ & 0.001 & 0.583 & 0.996 & 0.285 & 0.84 & 0.887 & 0.385 & 0.706 \\
\hline
\end{tabular}

Table 3: Correlations of resistin with hormones in the PCOS group.

\begin{tabular}{|c|c|c|c|c|c|c|c|c|c|}
\hline & & FSH & LH & LH/FSH & E2 & PRL & PRG & F.Test. & T.Test. \\
\hline \multirow{2}{*}{ Resistin } & $r$ & -0.034 & -0.005 & 0.009 & $0.322^{*}$ & -0.222 & $0.449^{* *}$ & $0.449^{* *}$ & 0.145 \\
\hline & $P$ & 0.799 & 0.971 & 0.943 & 0.012 & 0.089 & $<0.001$ & $<0.001$ & 0.27 \\
\hline
\end{tabular}

Table 4: Correlations of visfatin with age, obesity and IR parameters.

\begin{tabular}{|c|c|c|c|c|c|c|c|c|c|}
\hline & & Age & BMI & WHR & FBS & Insulin & $\underset{\text { IR }}{\text { HOMA2 }}$ & НОМА \%В & HOMA \%S \\
\hline \multirow[t]{2}{*}{ Visfatin } & $r$ & $-0.274^{*}$ & 0.081 & 0.093 & 0.106 & 0.158 & 0.061 & $0.262^{*}$ & -0.161 \\
\hline & $\mathrm{P}$ & 0.034 & 0.544 & 0.485 & 0.419 & 0.098 & 0.657 & 0.048 & 0.237 \\
\hline
\end{tabular}

Table 5: Correlations of Visfatin \& hormones in PCOS group.

\begin{tabular}{|c|c|c|c|c|c|c|c|c|c|}
\hline & & FSH & LH & $\begin{array}{l}\text { LH/ } \\
\text { FSH }\end{array}$ & E2 & PRL & PRG & F Test & T Test \\
\hline \multirow{2}{*}{ Vistafin } & $r$ & -0.063 & $.275^{*}$ & $.298^{*}$ & -0.048 & 0.071 & $0.449^{* *}$ & $.351^{* *}$ & 0.129 \\
\hline & $P$ & 0.633 & 0.034 & 0.021 & 0.718 & 0.59 & $<0.001$ & 0.006 & 0.215 \\
\hline
\end{tabular}


The patients' group was divided into two subgroups, 58 PCOS women with irregular cycles and 42 PCOS women with a regular cycle. The comparisons between regular and irregular PCOS women in different parameters are presented in Table 6 . Table 6 shows that there was a significant elevation in the mean age of the patients with the irregular cycle as compared with the regular cycle. Moreover, there were significant elevations in $I R, H O M A \% B$, and the serum levels of insulin, LH, free and total testosterone in patients with the irregular cycle as compared with the regular cycle.

Table 6: Comparison between PCOS patients with a regular and irregular cycle.

\begin{tabular}{|c|c|c|c|}
\hline Parameter & $\begin{array}{l}\text { PCOS with } \\
\text { Irregular Cycle } n=58\end{array}$ & $\begin{array}{l}\text { PCOS with Regular Cycle } \\
n=42\end{array}$ & $P$ value \\
\hline Age (year) & $32.58 \pm 3.97$ & $26.18 \pm 3.11$ & 0.007 \\
\hline BMI $\left(\mathrm{kg} / \mathrm{m}^{2}\right)$ & $27.01 \pm 4.84$ & $29.13 \pm 6.49$ & 0.08 \\
\hline W/H ratio & $0.80 \pm 0.17$ & $0.82 \pm 0.11$ & 0.09 \\
\hline FBS (mg/ml) & $84.95 \pm 24.68$ & $89.42 \pm 28.56$ & 0.062 \\
\hline Insulin ( $\mu \mathrm{IU} / \mathrm{ml})$ & 18.71 & 8.74 & 0.012 \\
\hline HOMA2IR & 2.39 & 1.77 & 0.009 \\
\hline НОМА\%В & 96.12 & 85.12 & 0.027 \\
\hline HOMA\%S & 88.77 & 92.08 & 0.061 \\
\hline FSH (mIU/ml) & 12.28 & 10.73 & 0.074 \\
\hline LH (mlU/ml) & 13.14 & 10.87 & 0.041 \\
\hline LH/FSH & 1.08 & 1.05 & 0.064 \\
\hline E2 (pg/ml) & 44.26 & 42.68 & 0.061 \\
\hline Prolactin(ng/ml) & 14.33 & 13.38 & 0.091 \\
\hline Progesterone(ng/ml) & 0.91 & 0.94 & 0.063 \\
\hline F.Testo. (pg/ml) & 4.38 & 2.14 & 0.024 \\
\hline T.Testo. (ng/ml) & 0.94 & 0.71 & 0.043 \\
\hline Visfatin (ng/ml) & 2.17 & 2.09 & 0.074 \\
\hline Resistin (ng/ml) & 3.08 & 3.12 & 0.061 \\
\hline
\end{tabular}




\section{Discussion}

The justification of this study was that to find out whether there is any association between PCOS and biomarkers (visfatin and resistin) and if they are able to predict IR in patients with PCOS, which has not been fully described well before. For this reason, this study was performed. Table 1 shows that patients who participated in this study were obese, the BMI was $28.72 \pm$ 4.66 , and this finding was concordant with previous result ${ }^{11}$ who reported that $41 \%$ of women with PCOS suffer from obesity. In PCOS, hyperinsulinemia and dyslipidemia are strongly associated with obesity. ${ }^{10}$

\section{Insulin}

PCOS is a well-known state of chronic hyperinsulinemia due to a compensatory mechanism for IR. Women with PCOS had hyperinsulinism (17.22 vs. $8.1 \mu \mathrm{lU} / \mathrm{ml})$ (Table 1), and this result was consistent with previous results. ${ }^{1,11}$ The explanation of this significant elevation in the serum level of insulin in women with PCOS this is mainly associated to decreased insulin clearance, IR and compensatory hyperinsulinism are the predominant metabolic defects in PCOS. However, hyperinsulinism, as well as being compensatory, can also express a condition of reduced insulin clearance. ${ }^{1}$

\section{Insulin Resistance}

The result of the current study (Table 1) indicated that, there was a significant increase in IR in women with PCOS and this result was concordant with previous results ${ }^{12,13}$ who published that IR is occurred in females with PCOS independently of obesity. In the early stages of IR, hyperinsulinemia occurs as an effort to maintain glucose tolerance. ${ }^{14}$ It was published that, PCOS is associated with the dysfunctional production of adipokines, initiating inflammation and IR. ${ }^{15}$

\section{Hyperandrogen}

PCOS is a common endocrine/metabolic disorder in women of reproductive age, characterized by chronic anovulation and hyperandrogenism, and this facts ${ }^{11,16}$ were consistent with the results of the current study, (Table 1) shows that there were significant elevations in the serum levels of testosterone $(4.18 \mathrm{Vs} 3.58 \mathrm{pg} / \mathrm{ml} ; 0.9 \pm 0.23$ Vs $0.71 \pm 0.32$ ) (free and total forms respectively) in patients group as compared with the control group. The explanation for hyperandrogenism that visfatin has an insulin-mimetic properties, ${ }^{9}$ accordingly it is very well known that hyperinsulinemia can stimulate ovarian androgen biosynthesis.

\section{Other Endocrine Hormones}

Table 1 shows that there were elevations in the serum $\mathrm{FSH}(11.89$ vs. $11.10 \mathrm{mlU} / \mathrm{ml})$, prolactin $(13.20$ vs. $11.97 \mathrm{ng} / \mathrm{ml})$, progesterone $(0.97 \pm 0.04$ vs. $0.94 \pm 0.04 \mathrm{ng} /$ $\mathrm{ml}$ ), but did not reach significant levels. In addition, there were significant elevations in serum levels of LH (14.12 vs. $11.13 \mathrm{mIU} /$ $\mathrm{ml}$ ) and estrogen 2 levels (67.58 vs. $38.69 \mathrm{pg} / \mathrm{ml}$ ). The explanation for these findings is that PCOS affects $5-10 \%$ of women of reproductive age, and is responsible for $50-70 \%$ of cases with anovulatory infertility. However, PCOS is an endocrine disorder characterized by disturbances in menstrual cycle, clinical and biochemical investigations of hyperandrogenism and polycystic ovaries. ${ }^{17}$ Therefore, PCOS is the most frequent cause of anovulation infertility and probably the most common endocrine disorder among women. ${ }^{14}$ Table 1 presents the $\mathrm{LH} / \mathrm{FSH}$ ratio value in patients with PCOS, this ratio was decreased in patients group as compared with the control group but did not reach the significant level while the result of another study ${ }^{16}$ that published the $\mathrm{LH} / \mathrm{FSH}$ ratio values in patients with PCOS were significantly reduced as compared with the controls (group A vs. C, $P<0.001$; group $B$ versus $C, P<0.05$ ), and no significantly difference between women with PCOS + BMI $\geq 25 \mathrm{~kg} / \mathrm{m} 2$ (group A) and $\mathrm{PCOS}+$ normal BMI (group B).

\section{Visfatin}

Many new proteins are strongly involved with PCOS physiopathology and IR, such as some adipocytokines visfatin. The expression of visfatin increases with 
obesity. ${ }^{18,19}$ It has been reported that visfatin levels are related well with body mass index (BMI) or percentage of body fat $^{20}$ and are increased in obese subjects. ${ }^{19}$ The patients who were enrolled in this study were considered as an obese patients whose their BMI was 28.72 \pm 4.66 which might contribute to a significantly increase the serum visfatin level. The current finding was consistent with previous results $^{13,21}$ emphasizing that visfatin could be a potential biomarker for PCOS. Many studies have indicated that visfatin was related with IR, and thereby may involve in the pathophysiology of PCOS. ${ }^{22}$

\section{Resistin}

Resistin is adipocytokine liberated by adipose tissue, and it is implicated in linking obesity with insulin resistance. Table 1 shows that there was a significant elevation in the serum level of resistin in patients with PCOS as compared with the control group and this result was concordant with previous results. ${ }^{13,14,23}$ It was reported that increased serum resistin level was related with obesity and IR ${ }^{24}$ and this finding was concordant with the result of the current study. Table 1 shows that patients who were enrolled in this study were obese their BMI $28.72 \pm 4.66$ and there was a significant elevation in the serum level of resistin in patients with PCOS as compared with the control group. The explanation of this significant elevation in the serum level of resistin was that serum resistin level was significantly high in PCOS patients ${ }^{22,25,26}$ due to the concurrence of insulin resistance. These studies support a positive correlation between resistin and insulin resistance in humans.

\section{Correlation among Studied Parameters}

Table 2 shows that there was a negative, weak significant correlation between age and resistin, while Table 3 shows that there were positive weak significant correlations between resistin and progesterone free ( $r=0.449, P \leq 0.001 ; r=0.449, P=<0.001$, respectively). However, it was published that there was a positive correlation between resistin with HOMA-IR, $\mathrm{LH}$, and LH/FSH $(P<0.05) .{ }^{23}$ Also, another study reported that no correlation was observed between resistin, BMI, IR, insulin, and serum androgen levels. ${ }^{27}$ Table 4 reveals that there was a negative, weak significant correlation between visfatin and age, as well as a positive weak significant correlation between visfatin and beta cell function. While, Table 5 was represented that there were positive weak significant correlation between visfatin and $\mathrm{LH}, \mathrm{LH} /$ FSH ratio, progesterone, and free testosterone $(r=0.275, P=0.034 ; 0.298$, $P=0.021 ; r=0.449, P<0.001 ; r=0.351$, $P=0.006$ respectively). However, another study revealed that women with PCOS, serum visfatin levels positively correlated with BMI $(r=0.23 ; P=0.047) .{ }^{16}$ Table 6 shows that there was a significant elevation in the mean age of the patients with the irregular cycle as compared with regular cycles, and this finding was not concordant with previous result ${ }^{28}$ who published that, the presence of regular cycles in older patients with PCOS.

\section{Conclusion}

It is concluded that there was an association between resistin, visfatin, and PCOS-related IR. Also, patients with PCOS have high IR as well as patients with PCOS women had significantly higher serum visfatin and resistin levels than age-matched healthy controls. These results suggested that significant elevations of the serum levels of visfatin and resistin might be factors involved in the pathogenesis of PCOS. So, visfatin and resistin were independently associated with IR in patients with PCOS. Accordingly, many recent proteins are now considered as potential new markers of IR in PCOS. So, visfatin and resistin may be novel independent biomarkers and predictors of $\mathrm{IR}$ in women with PCOS. It was found a strong connection between visfatin and resistin with IR in PCOS physiopathology. Many potential biomarkers that are considered as surrogate markers to 
simplify the assessment of IR. Further studies are needed to clarify and confirm the role of these proteins with IR in this syndrome.

\section{Competing interests}

The authors declare no competing interests.

\section{References}

1. Amato MC, Vesco R, Vigneri E, Ciresi A, Giordano C. Hyperinsulinism and polycystic ovary syndrome (PCOS): role of insulin clearance. J Endocrinol Invest 2015; 38(12):1319-26.

2. Matthews DR, Hosker JP, Rudenski AS, Naylor BA, Treacher DF, Turner RC. Homeostasis model assessment: insulin resistance and betacell function from fasting plasma glucose and insulin concentrations in man. Diabetologia 1985; 28:412-9.

3. Hoeger KM. Role of lifestyle modification in the management of polycystic ovary syndrome. Best Pract Res Clin Endocrinol Metab 2006; 20:293.

4. Spritzer PM. Polycystic ovary syndrome: reviewing diagnosis and management of metabolic disturbances. Arq Bras Endocrinol Metabol 2014; 58(2):182-7.

5. Thomas S, Suresh S, Sudheesh M, Vijayakumar $\mathrm{T}$. Association of insulin resistance with adipocytokinelevels in patients with metabolic syndrome. Indian J Clin Biochem 2015; 30(2):155 $-60$.

6. Hamada M, Abe M, Miyake T, Kawasaki K, Tada F, Furukawa S, et al. B cell-activating factor controls the production of adipokines and induces insulin resistance. Obesity 2011; 19(10):1915-22.

7. Lewandowski KC, Szosland K, O'Callaghan C, Tan BK, Randeva HS, Lewinski A. Adiponectin and resistin serum levels in women with polycystic ovary syndrome during oral glucose tolerance test: a significant reciprocal correlation between adiponectin and resistin independent of insulin resistance indices. Mol Genet Metab 2005; 85(1):61-9.

8. Ahmed MB, Ismail MI, Meki AR. Relation of Osteoprotegerin, Visfatin and Ghrelin to Metabolic Syndrome in Type 2 Diabetic Patients. Int J Health Sci 2015; 9(2):127-39.

9. Hug C, Lodish HF. Medicine. Visfatin: a new adipokine. Science 2005; 307(5708):366-7.

10. Panidis D, Kourtis A, Farmakiotis D, Mouslech T, Rousso D, Koliakos G. Serum adiponectin levels in women with polycystic ovary syndrome. Hum Reprod 2003; 18(9):1790-6.

11. Gul OO, Cander S, Gul B, Açıkgoz E, Sarandol E, Ersoy C. Evaluation of insulin resistance and plasma levels for visfatinand resistin in obese and non-obese patients with polycystic ovary syndrome. Eur Cytokine Netw 2015; 26(4):73-8.
12. Huma N, Patra SK, Binita G, Anju J, Chitra R. Study of Association of Leptin and Insulin Resistance Markers in Patients of PCOS. Indian J Clin Biochem 2016; 31(1):104-7.

13. Vejrazkova D, Lischkova $O$, Vankova $M$, Stanicka S, Vrbikova J, Lukasova $\mathrm{P}$, et al. Distinct response of fat and gastrointestinal tissue to glucose in gestational diabetes mellitus and polycystic ovary syndrome. Physiol Res 2017; 66(2):283-92.

14. Bertha P, Irawan Y, Muchtaruddin M, Andi W. Serum adiponectin and resistin in relation to insulin resistance and markers of hyperandrogenism in lean and obese women with polycystic ovary syndrome. Ther Adv Endocrinol Metab 2011; 2(6):235-45.

15. Mannerås-Holm L, Leonhardt $H$, Kullberg J, Jennische E, Odén A, Holm G, et al. Adipose tissue has aberrant morphology and function in PCOS: enlarged adipocytes and low serum adiponectin, but not circulating sex steroids, are strongly associated with insulin resistance. $\mathrm{J}$ Clin Endocrinol Metab 2011; 96(2):E304-11.

16. Jin JK, Young MC, Min AH, Min JK, Soo JC, Sun MK, et al. Serum visfatin levels in non-obese women with polycystic ovary syndrome and matched controls. Obstet Gynecol Sci 2018; 61(2):253-60.

17. Mendonça HC, Montenegro RM, Foss MC, Silva De Sa MF, Ferriani RA. Positive correlation of serum leptin with estradiol levels in patients with polycystic ovary syndrome. Braz J Med Biol Res 2004; 37(5):729-36.

18. Fukuhara A, Matsuda M, Nishizawa M, Segawa $\mathrm{K}$, Tanaka M, Kishimoto K, et al. Visfatin: a protein secreted by visceral fat that mimics the effects of insulin. Science 2005; 307(5708):42630.

19. Zahorska-Markiewicz B, OlszaneckaGlinianowicz $M$, Janowska J, Kocełak $P$, Semik-Grabarczyk E, Holecki M, et al. Serum concentration of visfatin in obese women. Metabolism 2007; 56(8):1131-4.

20. Berndt J, Klöting N, Kralisch S, Kovacs $P$, Fasshauer M, Schön MR, et al. Plasma visfatin concentrations and fat depot-specific mRNA expression in humans. Diabetes 2005; 54(10):2911-6.

21. Sun $Y$, Wu Z, Wei L, Liu C, Zhu S, Tang S. High-visfatin levels in women with polycystic ovary syndrome: evidence from a meta-analysis. Gynecol Endocrinol 2015; 31(10):808-14.

22. Seow KM, Hwang JL, Wang PH, Ho LT, Juan CC. Expression of visfatin mRNA in peripheral blood mononuclear cells is not correlated with visfatin mRNA in omental adipose tissue in women with polycystic ovary syndrome. Hum Reprod 2011; 26(10):2869-73.

23. Wang $Y$, Xie X, Zhu W. Serum adiponectin and resistin Levels in patients with polycystic ovarian syndrome and their clinical implications. 
J Huazhong Univ Sci Technol Med Sci 2010; 30(5):638-42.

24. Azuma K, Katsukawa F, Oguchi S, Murata M, Yamazaki H, Shimada A, et al. Correlation between serum resistin level and adiposity in obese individuals. Obesity Res 2003; 11(8):9971001.

25. Chen X, Jia X, Qiao J, Guan Y, Kang J. Adipokines in reproductive function: a link between obesity and polycystic ovary syndrome. J Mol Endocrinol 2013; 50(2):R21-37.

26. Carmina E. Obesity, adipokines and metabolic syndrome in polycystic ovary syndrome. Front Horm Res 2013; 40:40-50.

27. Yilmaz M, Bukan N, Demirci H, Oztürk C, Kan E, Ayvaz G, et al. Serum resistin and adiponectin levels in women with polycystic ovary syndrome. Gynecol Endocrinol 2009; 25(4):246-52.

28. Elting MW, Korsen TJ, Rekers-Mombarg LT, Schoemaker J. Women with polycystic ovary syndrome gain regular menstrual cycles when ageing. Hum Reprod 2000; 15(1):24-8. 